\title{
Friction will be published bimonthly from 2019
}

\author{
Jianbin LUO \\ Editor-in-Chief \\ State Key Laboratory of Tribology, Tsinghua University, Beijing 100084, China \\ (C) The author(s) 2019.
}

6 years have passed since the journal Friction launched in 2013. Looking back with the 6 years' publication, we are happy to state that the journal has been a success from the very start, both in terms of the quantity and quality of manuscripts received.

Already, 779 papers have been submitted to Friction and 258 have been accepted. 202 articles were published officially in 2013-2018, more 50 articles are online first waiting for publication. Furthermore, the inflow of manuscripts is still increasing, in order to further reduce the publication time to meet this increasing demand from both our readers and authors, the publishers and editors have decided to change the journal publication frequency from quarterly to bimonthly, effective Issue 1, Volume 7 (2019), with a regular schedule such as: Issue 1 (February); Issue 2 (April); Issue 3 (June); Issue 4 (August); Issue 5
(October); Issue 6 (December). By making this change, we hope that the increased publication frequency will provide earlier exposure of exciting work to our readers and increase the number of published articles. And we could assure you that the quality control and timeliness of the manuscript review process will not be affected by this change. We will further tighten the quality control by imposing higher standards in accepting papers.

Last but not least, I would like to express our sincere appreciation for the authors, reviewers, readers, editorial board members and publishers for helping to make the journal a success. We welcome your continued readership and article submission, and look forward confidently to Friction's continued progress in the years ahead. 